\title{
Creativity Enhancing Methods in the Educational Process
}

\author{
A. B. Reshetnikova* \\ Department of English Philology, Pedagogical Institute, Kryvyi Rig, Ukraine \\ *Corresponding author: abr1981@mail.ru
}

Received September 30, 2013; Revised October 11, 2013; Accepted November 25, 2013

\begin{abstract}
In this article the methods of formation of future teachers' creativity in the process of learning philological disciplines is considered. Methods of different authors were worked out. The analyze of literature according to our topic helped us to separate out such methods that are important for the process of formation of students' creativity. We investigated not only methods but also different forms of cognitive activity where the main thing is co-operation between teacher and students. Methods that are based on the role-playing and problemsituational tasks have influence on different spheres of personality: cognitive, emotional, motivated and psychological. It encourages to the further active development of pedagogical culture and creative activity. The main points, problems and ways of their overcoming are revealed. The given results of experiment prove the importance of introduction in the system of education the proposed methods. The use of such active work is evolution of creative thinking, intellectual skills, communicative abilities of future master of Philology. A modern student will be the creator in the future, and that is why it is necessary not only to work with his personality, but form his professional consciousness.
\end{abstract}

Keywords: creativity, methods, technologies, role- playing situation, seminars

Cite This Article: A. B. Reshetnikova, "Creativity Enhancing Methods in the Educational Process." American Journal of Educational Research 1, no. 11 (2013): 543-547. doi: 10.12691/education-1-11-15.

\section{Introduction}

Nowadays creativity is a very important character of modern personality. Many authors try to find the best ways how to improve the procedure of formation of creativity. We have learned a number of scientific articles and came to the conclusion that this question is still actual and is not detached. The process of formation of creativity will be successful if we follow some important rules. We think that these rules are methods of formation of creativity in the process of learning and they must be used very carefully and systematically.

\section{Objectives of the Study}

The main objectives of this research are to find the best methods of formation of creativity and prove its importance. The following steps should be done:

1. To analyze the methods of formation of creativity.

2. To propose specially developed system of formation of creativity.

3. To examine the status of students' creativity in modern universities.

4. To conduct an experiment and compare the results.

5. To provide recommendations to achieve effective formation of creativity.

\section{Methodology}

In the process of formation of creativity we must differ such terms as 'methods' and 'technology'. A. Rachimov proposes next definition. Methods - is the system of approaches, processes, rules of teaching, common directions how to conduct the lesson. Technology of education proposes the detail working out of the whole script with detachment of components and logic of student's educational activity and teacher's following work [4].

\subsection{The Analysis of Methods}

Among the most famous authors that worked out the methods of formation of creative qualities are: E. Torrens and E. De Bono. They were the first scientifics who tried to find the best methods of formation $f$ creativity. E. Torrens's methods is first of all the training that consists of several stages. During every stage the evolution of creative thinking is happened. E. Torrens emphasized thinking as the main implement of creativity. But this instrument must be free from thoughts and models imposed by the society. R. Krachfild linked the formation of creativity with solving of creative tasks. He produced the methods where the main elements were creative tasks. The famous psychologist, we must underline that he is not a teacher, E. De Bono created his own methods of 
formation of creative thinking on the bases of playing activity. He considered that personality is in the mod for creativity in the process of play.

T. Tarasenko studied the facts of formation of future teachers' professional culture and accented that using of communicative and role-playing methods are very useful for the evolution of speaking activity [6].

S. Ovcharov analyzed the process of formation of creativity and proposed to use:

1. Method of problem teaching. The aim of it is mastering of material with the help of solving of special cognitive tasks.

2. Developmental teaching. The main accent is on teaching activity that helps to develop theoretical thinking and every pupil's personality.

3. Pedagogical engineering. The main task is the organization of the educational activity. The aim is to get authors' educational product.

4. Heuristic teaching that has elements of reproductive activity. This method has the aim to develop the student and make him the subject and the engineer of his own education, organizer of his knowledge [3].

R. Krachfild worked out one of the first methods of the development of creativity. He thinks that the formation of creativity can be effective only with the help of creative tasks.

\section{Methods of Creativity Formation}

The analysis of literature according to our topic helped us to separate out such methods that are important for the process of formation of students' creativity. They are:

a. The bright examples of stimulating of interest to learn English (it helps to be in the mood for thinking).

b. The search of unusual analogies and opportunities for showing emotions (surprise and distrust ensure the further, self - contained education for the searching of truth).

c. Different games that have the aim to develop creative qualities (the realization of intellectual qualities and opportunities of creative thinking).

d. Situation of alternative and question (stimulation of activity and possibility to have several answerers).

For the development of thinking during the solving of different creative tasks we can use methods that are united into two groups:

- logical methods (priority to the logical thinking).

- heuristic methods ( the solving of educational task with the help of stimulation of intuitive thinking for the generation of new idea).

We think that in the process of formation of creativity it is necessary to use heuristic methods. We completely agree with S. Susoeva: "Heuristic methods stimulate vivid thinking in the process of solving of educational problem. It helps to use all its advantages and clearly understand the situation" [7]. It is known that there is a connection between divergent thinking and creativity. Heuristic methods propose to use divergent thinking and help to improve the process of formation of creativity.

When we look for new creative idea it is necessary to follow some heuristic rules for reaching positive result: 1) examine the problem from different points of view; 2) it is forbidden to give corrections and express the idea about presented point of view; 3) all points must be written for the common look; 4) students' respect and positive mood; 5 ) the opportunity to combine different points of view for the searching of right decision; 6) it is necessary to express the opposition idea without aggression and with respect; 7) at the end of discussion various positive propositions are supported; 8) the sum of done work.

\subsection{Heuristic Methods}

We defined such heuristic methods:

1. The method "brain storm" (the bases of this model is Socrates' heuristic dialogue. This method proposes to accumulate new idea, form another view and independent thinking during the solving of educational problem. At this time teacher must follow psychology- pedagogic rules. These positions are very important and their ignoring will not give opportunity to achieve the aim. The main rules are: informal situation, the absent of critics from teacher and other students, the feeling of equality of rights, respect between students, students' stimulation to self - expression and help from teacher's side in the case of problem with presentation of idea). This method is good to use during the lesson when the task is "Prove your idea".

2. The method "key questions" (the main idea of this method is the search of new information, the formation of another ways and strategies for solving educational problem. It is known that good asked question helps to give right answer and it activates the process of education. The important principle is the division of problem question on components.

3. The method "multivariate matrix" (the use of associations helps to find idea that will be effective for solving of educational problem. The main principle is cooperation in the group and the use of experience.

4. The method "inversion" (the main sign of this method is focusing on search of new idea with the help of unusual and illogical views. The main principle is the development of dialectics of thinking and searching of very unexpected variants.

5. The method "synectics". To realize this method we must understand the term "synectics". The author of this method is J. Gordon. He thinks that "synectics" is the combination of different elements. The main principle is analogy. The use of abstract and specific analogies proposes the identification with the subject of creative activity and intensifies fantasy.

We consider that the use of mentioned methods promotes the formation of future teachers' creativity.

At the same time U.Azarov analyzed the pedagogical practice and came to the conclusion that teacher's personality has influence on the choice of the methods [1]. There are no universal methods and every teacher must select those ones that will be effective for the formation of creativity. Future master of Philology must be ready for "modeling of the whole process that has orientation on the development of creative personality" [5].

L. Manchylenko singled out forms and methods that are the most successful for the formation of creativity: seminars, discussions, communication (the aim is to form pedagogical skills); demonstrations (development of abilities to organized individual activity); practical and laboratory work (mastering of necessary professional knowledge); pedagogical games and tasks (formation of individual creative activity) [2]. 


\subsection{Forms of Cognitive Activity}

We investigated not only methods but also different forms of cognitive activity where the main thing is cooperation between teacher and student. The result of such work is evolution of creative thinking, intellectual skills, and communicative abilities of future master of Philology. We are sure that success of formation of creativity depends on forms and methods that stimulate activity, original thinking during learning imitate educational situations. Proposed forms give every participant opportunity to show independent, originality. It encourages showing positive emotions and this is the guaranty of active educational interest in learning English. Different kinds of seminars stimulate the formation of creativity. The following seminars are good for the formation of creativity:

1. Seminar - conversation. The aim is the discussion of different topics for the demonstration of knowledge, formed communicative and creative skills, activity and independence. Theme: «Shopping ». «A good advertising can help to sell a product».

2. Seminar - debate. The aim is the solving of different educational problems with the help of individual idea and creative upholding of the personal position. Theme: «Health». «Many people suffer the effects of passive smoking».

3. Seminar - discussion. The aim is the expression of various and opposite points of view. The result is one right decision of the education problem. Theme: «Cinema». «Soap operas help to educate pupils about what is right and what is wrong».

4. Seminar - dialogue. The aim is the development of communicative skills, transformation of information on the verbal level, speed of reaction on opponent's reply. Theme: «My future job is a teacher». «Worrying makes people do badly in job interviews».

5. Seminar - role situation. The aim is working with different role situations for showing attention, creative qualities and opportunities to be creative personality at the lesson. Theme: «Travelling». «Would you ever consider going to leave your native country?».

6. Seminar - gaming. The aim is the union of theoretical knowledge and practical skills with use of creative thinking during gaming. Theme: «Personality». «Optimists perform better than pessimists».

7. Seminar - contest. The aim is to define the level of future teacher's acquired skills to creatively solve educational problems, work with interest, originally express own idea and present it on the professional level. Theme: «Changes in life». «What effect has success on a person?».

8. Seminar - presentation of project. The aim is to form the ability of master of Philology to the independent creative activity. Theme: «Mass media». «Reading the news on a computer screen is less enjoyable than reading it in a newspaper».

The success of use this seminars during the formation of students' creativity depends on pedagogical conditions that have influence on this process. And we must admit that the result of the formation of this difficult and personal creation depends on the way how these conditions are fulfilled. We considered that the main conditions are:
1) The theme that students are going to discus. It must be interesting, have practical meaning for the further professional formation of future teachers.

2) To express the main idea it is necessary to have good vocabulary. It helps to tell the idea correctly.

3) The creation of healthy psychological atmosphere that helps to co-operation in common creative development.

4) The inclusion of students' abilities and level of their creative capabilities during the solving of task.

\subsection{Non-Standard Lessons}

For the formation of creativity we can use non-standard lessons. Non- standard lessons - are the lessons which belong to the common classification but free from usual patterns in the structure. Its typical feature is domination of creative situations that form good conditions for the evolution of students' creativity. [7]. We can admit that traditional and non - standard lessons have the same aim, but the way how to reach it is different. And this is the main characteristic. For the non- standard lessons the following forms are good: seminar - debate, seminar competition, seminar - conference, lessons - "different kinds of role - plays" and others.

For the formation of creativity it is good to use different situations.

Situation is a created pedagogical reality that has the aim to make the students more active. It helps them to find creative idea. For example: Situation 1. You are the owner of the travel agency. Speak on the best city for the rest in Ukraine; Situation 2. You are on TV. Speak about fashion in your country; Situation 3. You are the owner of the shop. Speak on the pros and cons of this business.

It is proved that educational trainings played a very important role in the process of formation of creativity. We can name the following trainings:

a. Role- play (acting of different roles for working out knowledge).

b. Business - play (imitation of various professions for showing creative qualities).

c. Case (problem situation that students have to solve with the help of analyzing of information).

d. Games - warm up( tasks that have an influence on the dynamic of educational group).

\section{Experimental Research}

We considered that formation of students' creativity will be effective and successful if we use the following methods in the educational process. To prove our idea we decide to have an experiment. The main aim of it is to check our suppositions and find out the results of its use in practice.

During this experiment we divided students into two groups. The first group (experimental). In this group we used proposed methods. And the second group (control). In this group the educational process was according to the traditional system without making good use of creative technologies.

The results of this experimental group say about the increasing of the level of students' educational motivation that happened first of all due to the fact that we used proposed methods and kept them strictly. The results of 
control group were not so good and even the level of their creativity was the same.

\subsection{Motivation}

Now it is better to look through more carefully every step of this experiment to see the details of formation of creativity and its qualities. Motivation in the control group increased only on $2 \%$ on every level. In experimental group (high level - from $14 \%$ to $34 \%$; medium level from $48 \%$ to $62 \%$; low level - from $38 \%$ to $4 \%$ ). And this is a guaranty of new knowledge that is necessary for the professional position of creative personality in future.

The active use of playing technologies and methods increased in students the burning desire to master knowledge and to become more qualify specialists. In the control group the number of students even decreased (high level from $28 \%$ to $24 \%$; medium level from $38 \%$ to $34 \%$; low increased from $34 \%$ to $42 \%$ ), in experimental group the number of students increased (high level from $28 \%$ to $42 \%$; medium level from $38 \%$ to $43 \%$; low level decreased from $34 \%$ to $15 \%$ ).

\subsection{Activity}

Students' independence and activity in the control group decreased by $10 \%$ on every level, except for the high. In the experimental group due to the use of creative tasks, presentations, debates, which pushed the students to make independent judgments and find a way out of the academic problem in the educational process, the number of students increased (high level from $10 \%$ to $35 \%$; medium level from $45 \%$ to $55 \%$; le level from $45 \%$ to $10 \%)$.

Thanks to the playing technologies and a variety of educational problems situations, students went from subroutines and began to solve the problems with innovation, address the issues of innovation, boldly offering their own creative ways.

In the experimental group the number of students increased (high level from $16 \%$ to $30 \%$; medium level from $44 \%$ to $60 \%$; low level from $40 \%$ to $10 \%$ ). In the control group we have such changes: high level decreased from $16 \%$ to $14 \%$; medium level increased from $44 \%$ to $46 \%$; low level did not change.

Suggested methods of formation of creativity on the basis of communicative and creative approach significantly increased the number of students with the presence of foreign language competence in the experimental group (high level from $10 \%$ to $30 \%$; medium level from $45 \%$ to $60 \%$; low level from $45 \%$ to $10 \%)$. In the control group the number of students changed not significantly (high level from $10 \%$ to $15 \%$; medium level from $45 \%$ to $50 \%$; low level from 45 to $35 \%$ ). Proposed methods helped to create good moral atmosphere, trust relationship between students and teacher and set on effective co - operation in the process of formation of future teachers' creativity.

\subsection{Interest in Educational Process}

After analyzing the results of the students in the control and experimental groups, we came to the conclusion that the traditional method is not conducive to the formation of creativity for future philologists. If at the beginning of study, the students preferred reproductive task (tasks that give knowledge through explanations and do not form the ability to use them in practice; it is only piece of information that does not contribute to the formation of future teachers' creative qualities), so after completion of the experiment they independently and consciously, without a hint from the teacher chose reproductive creative tasks (tasks that focuse on a conscious and independent search for new information, which objectively is not new) and creative tasks (tasks that contribute to show creative qualities and skills).

Comparative analysis shows that the students' interest of the experimental group to creativity increased, and therefore the preference was given to the tasks of creative direction. By $55 \%$ increased the popularity of creative tasks, the demand for reproductive and creative tasks declined by $25 \%$ and reproductive tasks decreased to $15 \%$.

In the control group, only by $5 \%$ increased the indicator of students' aspirations to the creative nature of the work. Attitudes to reproductive and creative nature of the task have not changed significantly.

According to these results, we can confidently say that the students in the control group are not interested in educational process and the process of their professional formation.

The use of the problem-situation and playing technologies in the process of studying of special disciplines stimulates pedagogical imagination and creative thinking, makes to search new knowledge, promotes creation of new educational results and refusal from standard actions, adapts to various situations that can happen in real life, forms morals and values of future teachers.

\subsection{Level of Acquired Knowledge}

The main indicator of professionalism is the level of acquired knowledge and aspiration for further development of the professional qualities of personality. The results completely correspond our expectations and reflect the improvement and intensification of students' cognitive position during studying special disciplines. Communicative - creative approach to the teaching of professional disciplines awakens the student's inner reserves, forms quantitative and qualitative characteristics of the creative personality.

In the experimental group percentage of students who are not interested in learning, have superficial knowledge and limited vocabulary decreased by $25 \%-40 \%$ and the percentage of students who improved their results and have high level of knowledge of a foreign language doubled.

The data of the control group indicated changes, but, unfortunately they are not dynamic.

\section{Levels of Creativity}

Determination of the levels of creativity was carried out according to the following scale:

- from 3,9 to 2 -high level;

- from 2,0 to 1,5 -medium level;

- from 1,5 to 1,0 -low level.

The analysis of the results proved dynamic development of the future teachers-philologists' creative 
qualities. If we compare the original data with obtained one, the following conclusions can be done. The number of students who had low level of creative qualities decreased from $70 \%$ to $20 \%$ (hence the use of the proposed forms and methods of training contributed to the formation of creative qualities), medium level increased from $25 \%$ to $45 \%$ (the provided program stimulates the further development of students' creative qualities), high level of formation of creative qualities rose from $5 \%$ to $20 \%$ (the result is fixed and it sets to the further professional development).

According to this test, the number of students who had high level of formation of creative qualities increased by $3 \%$; medium level changed from $25 \%$ to $32 \%$; low level of formation of creative qualities fell from $70 \%$ to $60 \%$.

\subsection{The Level of Criteria of Creativit}

To confirm the results, we conducted another survey. Each criteria of creativity of a future teacher's personality corresponds the indicator. The criteria were following: «3» - the greatest manifestation of creative qualities; «2» the medium manifestation of creative qualities; «1» - low manifestation of creative qualities; «0» - the absence of any information.

Every student got 12 marks.

Counting was conducted using the formula

$$
K \mathrm{~m}=(\mathrm{Zm}+\mathrm{Zc}+\mathrm{Ze}+\mathrm{Zv}-\mathrm{c}): 42,
$$

Where:

$\mathrm{Km}$ - factor that is responsible for the level of creativity.

$\mathrm{Zx}$ - the resulting sum of points.

$\mathrm{x}=[\mathrm{m}, \mathrm{c}, \mathrm{e}, \mathrm{v}-\mathrm{c}]-$ the designation of components of the structure of a creative person: «m» - motivational, «C» cognitive, «e» -emotional, «V-C» - verbal - creative.

42 - is the maximum possible number of points that can be obtained during the evaluation of the 14 criteria on a 3point scale.

The indicators gave the opportunity to determine the boundary of levels of formation of creativity using the 3point assessment system:

- from 1,0 to 0,85 point - high level;

- from 0,84 to 0,50 point - medium level;

- from 0,49 to 0,33 point - low level;

- from 0,32 point - the level of initial forming.

\subsection{The Results of Data}

Information obtained in the course of the establish experiment shows that low level (55\%) is mainly dominated.

Results of the formative experiment differ significantly. Medium level (45 \%) and high level (30 \%) are dominated. Indicators have improved significantly and it proves that the proposed methods contribute to the development and successful position.

The results in the control group show positive changes. But if we compare them with the experimental group these changes are not substantial: a high level changed by $5 \%$; the medium level -by $10 \%$; low level by $15 \%$.

In the course of further research we considered that it is necessary to pay attention to the level of formation of the components of creativity and explore their possible changes.
Indicators evidence about the significant changes in the experimental group. High level improved from $4 \%$ to $39 \%$; medium level increased from $35 \%$ to $52 \%$; low level decreased from $61 \%$ to $9 \%$. Changes in the control group are minimal: high level has not changed; medium level decreased from $35 \%$ to $30 \%$; low level increased from $61 \%$ to $65 \%$.

The analysis of the received results allows us to make a conclusion. Implementation in the practice the proposed method has a positive influence on the effectiveness of formation of creativity.

In the experimental group all components of creativity have improved. The indicators have increased significantly. In the control group the level of components of creativity has remained almost the same.

\section{Conclusion and Recommendation}

Thanks to the proposed methods of formation of creativity we reached the aim of our study on the formation of creativity for future teachers. The proof of this is the comparative analysis of results before and after the experimental work in the experimental and control groups.

A modern student will be the creator in the future, and that is why it is necessary not only to work with his personality, but form his professional consciousness.

Methods that are based on the role-playing and problem-situational tasks have influence on different spheres of personality: cognitive, emotional, motivated and psychological. It encourages to the further active development of pedagogical culture and creative activity.

Unfortunately, modern youth have other priorities. Initiative, arrogance and ambition are on the first place. Such values as honesty, responsibility and diligenceare are not significant and have little meaning for young people. Proposed methods help to correct moral principles and indicate the possibility of positive changes.

The feeling of independence, the availability of equitable relations between fellow students and the lack of authoritarianism from the teacher guarantee the students' desire to study and become a creative person. This helps to have a feeling of psychological security, and that is why the whole concentration, strength and energy are directed on search of new knowledge and development of nontypical actions.

\section{References}

[1] Azarov, U.P, The art to bring up, Prosveshenie Publishers, Moscow, 1979, 255.

[2] Manchulenko,L.V, Formation of future teacher's creative style in active work, Ruta Publishers, Chernovzi, 2007, 76.

[3] Ovcharov, S. "Methodological ways to the process of formation of future teachers' creative potential”, Problems of future teacher's preparation №4(2), 7-12, 2011.

[4] Rahimov, A.Z, The formation of pupil's thinking in the process of study, Ufa, 1988, 168.

[5] Suchenko, T.I, "The particular qualities of the personally oriented pedagogical process”, Pedagogy and psychology of formation of creative personality, №19, 3-6, 2001.

[6] Suschenko,T.I, Pedagogy and psychology of creative personality's formation, Zaporozie, 2008, 312.

[7] Susoeva, S.A, Pedagogical creativity, Karavella Publisher, Kiev, 1998, 150. 